\title{
Evaluation of Rutting Performance of Asphalt Mixture with Driving Wheel Pavement Analyzer
}

\author{
Xu Cai, ${ }^{1}$ Duanyi Wang, ${ }^{2}$ Wenke Huang, ${ }^{1}$ Jiangmiao Yu, ${ }^{2}$ and Cheng Wan ${ }^{3}$ \\ ${ }^{1}$ School of Civil Engineering, Guangzhou University, Guangzhou 510006, China \\ ${ }^{2}$ School of Civil Engineering and Transportation, South China University of Technology, Guangzhou 510641, China \\ ${ }^{3}$ Guangxi Key Laboratory of Disaster Prevention and Engineering Safety, Guangxi University, Nanning 530004, China
}

Correspondence should be addressed to Xu Cai; cx_caixu@163.com

Received 22 February 2017; Revised 23 May 2017; Accepted 27 June 2017; Published 14 September 2017

Academic Editor: Meor Othman Hamzah

Copyright (c) $2017 \mathrm{Xu}$ Cai et al. This is an open access article distributed under the Creative Commons Attribution License, which permits unrestricted use, distribution, and reproduction in any medium, provided the original work is properly cited.

\begin{abstract}
Rutting is common pavement distress, which leads to lower riding comfort for road users and high maintenance costs. One of the commonly used tests is the simulation test with wheel tracking devices. Here, a new rutting test system has been developed based on the "Driving Wheel Pavement Analyzer" (DWPA) to evaluate the rutting performance of asphalt mixtures. This study conducted three types of rutting tests to validate feasibility, reliability, and accuracy of DWPA test. The results indicated that the DWPA test provided more information on ruts and enabled us to distinguish the performance of materials. The $C_{\mathrm{DWPA}}$ index is better suited to reflect the rutting resistance of the material, which is highly correlated to the APA rutting index and the rutting test index of China according to the grey relational analysis results.
\end{abstract}

\section{Introduction}

Rutting has long been a major concern for flexible asphalt pavements. It is also one of the most common permanent pavement deformations due to repetitive traffic loads, which gradually accumulate small pavement deformations that appear as longitudinal depressions in the wheel paths of roadways [1]. Not only is rutting a concern for driving safety, but also it reduces pavement strength and the service life, increasing the difficulty of pavement maintenance as well as its cost. Therefore, finding an appropriate rutting test is the most important project for asphalt mixture performance evaluation [2-5].

According to the 19th world road conference (participants were, e.g., Great Britain, France, Italy, Canada, and other countries), 16 countries provided survey data and most countries agreed that using the Marshall design method of asphalt mixture stability and flow value index did not result in a good correlation with the actual permanent pavement deformation. Even if Marshall stability and flow value index of the asphalt mixture are satisfied, the rutting of pavement still cannot be effectively controlled at high temperatures.
Therefore, it has been required to use the British Transport and Road Research Laboratory (TRRL) or the French Laboratories Central des Ponts et Chaussees (LCPC) rut testing device for additional testing. Furthermore, a variety of methods have been developed to evaluate the performance of asphalt mixtures at high temperature.

With respect to various studies on rutting performance of pavement materials, a variety of rutting test equipment was developed [6-20], such as the Asphalt Pavement Analyzer (APA), the Hamburg Wheel Tracking Device (HWTD), the French Pavement Rutting Tester (FPRT), the Purdue University Laboratory Rutting Instrument (PURWHEEL), South Africa's Small Mobile Loading Simulator (MMLS3), the Multiwheel Rutting Instrument (RLWT), and China's Rutting Test Machine. These rutting tests have similar working principles; that is, the asphalt test specimen is tested under a specified temperature, load conditions, and load repetitions. Then, the amount of vertical deformation is measured and relevant indicators are calculated. Currently, different types of rutting devices and different methods in terms of the performance of the test are in use. Consequently, 

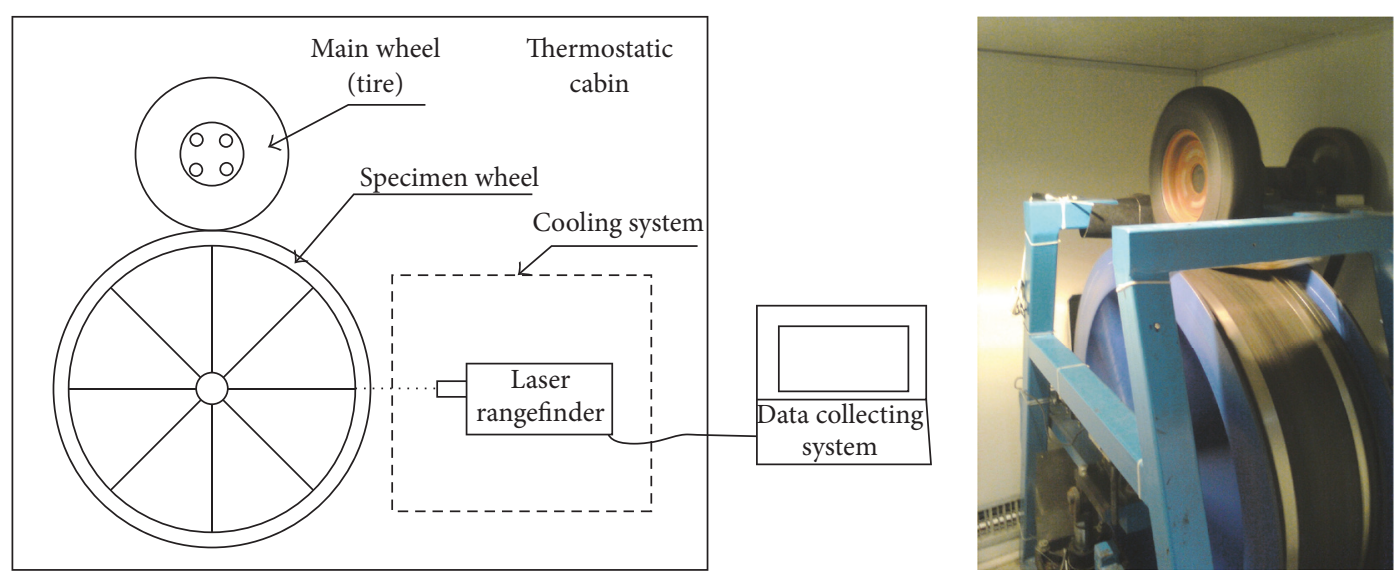

FIGURE 1: DWPA rutting test system.

different rutting equipment and test methods for materials have great influence on the evaluation of results: different loading methods, test temperature, wheel load, and specimen size will lead to differences of test results.

However, the above types of rutting testers have a common characteristic, that is, the use of towed test wheels, and therefore cannot simulate the horizontal shear force on the road surface, resulting in rutting test results inevitably conflicting with the actual road rut. Wang et al. [21] summarized the characteristics of the rutting test equipment commonly used in China and abroad and proposed that the current rutting test equipment still had room for improvement. For example, the wheel load, test speed, and tire pressure should be variable to simulate the actual loading condition of the pavement. Due to the complexity of the actual pavement stress, the South China University of Technology designed and developed the "Driving Wheel Pavement Analyzer" (DWPA), which uses the automobile tire drive specimen wheel rotation system. This device can accurately represent the conditions between pavement and tire stress, and also corresponding load, tire pressure, speed, and environmental conditions can be set according to different test. This study introduces the choice of the rutting evaluation index and also opens a new direction for the rutting analysis of asphalt mixture.

\section{Composition of the Rutting Test System}

The main rutting test system used for our study is the "Driving Wheel Pavement Analyzer" (DWPA), which is a device that can be used for road surface pavement material durability evaluations, pavement skid resistance performance evaluations, and pavement noise evaluations. The accelerated loading core part includes the driving wheel (an actual tire) and the specimen wheel. The specimen wheel is composed of eight (8) samples of asphalt mixtures. Typically, it takes about one week to mold and mount these specimens onto the wheel.

Figure 1 shows that rutting data measurement and acquisition systems are mainly composed of a laser displacement sensor, the data collecting system, and the temperature control system structure. Two (2) KEYENCE high precision laser displacement sensors (with a maximum resolution of $5 \times 10^{-3} \mathrm{~mm}$ ) are used to measure the rutting depth. The sensors are installed tilted to improve the amount of received light. Furthermore, a specially designed adjustable bracket is used to bring the sensors as close to the target as possible (as shown in Figure 2). We set the distance between both displacement sensors to $50 \mathrm{~mm}$ according to the tire width $(80 \mathrm{~mm})$. To reduce the impact of temperature changes on the measurement accuracy, the displacement sensor is integrated within a specially designed temperature control system, which is able to ensure that the sensor temperature stays below $30^{\circ} \mathrm{C}$.

To measure the rutting depth on the center and the edge of the wheel track, one (1) of the laser displacement sensors is located centrally to capture the displacement in the middle of the wheel track, while the other one is placed on the edge to capture the amount upper convex on the edge of the wheel track (as shown in Figure 3). According to the measured data, the rut depth can be calculated. Furthermore, the calculation method is consistent with the actual rut depth calculation method. The displacement data of the edge will help to determine the time and amount of when and how much the shear deformation occurs on the material. The vertical displacement signal of each piece of specimen is received via digital converter and converted into rut depth. These data are stored by the data acquisition system, which is designed with real-time data query, historical data query, and data export function.

The DWPA device uses one pneumatic tire with a width of $80 \mathrm{~mm}$ (maximum inflation pressure can reach $720 \mathrm{kPa}$ ) and the axial load can be selected between 1.5 and $3.5 \mathrm{kN}$ (the maximum can reach $4.5 \mathrm{kN}$ ). However, in our research, tire inflation pressure was set to $700 \mathrm{kPa}, 2.5 \mathrm{kN}$ for the axial load, and $0.7 \mathrm{MPa}$ for the position of contact pressure. The wheel speed can be adjusted between 0 and $40 \mathrm{~km} / \mathrm{h}$. Considering data transmission and acquisition frequency limit, we used $3.23 \mathrm{~km} / \mathrm{h}$ as a stable wheel speed. The test temperature was adjustable between 20 and $80^{\circ} \mathrm{C}$, and according to the conditions to perform the rutting test in China and abroad, 

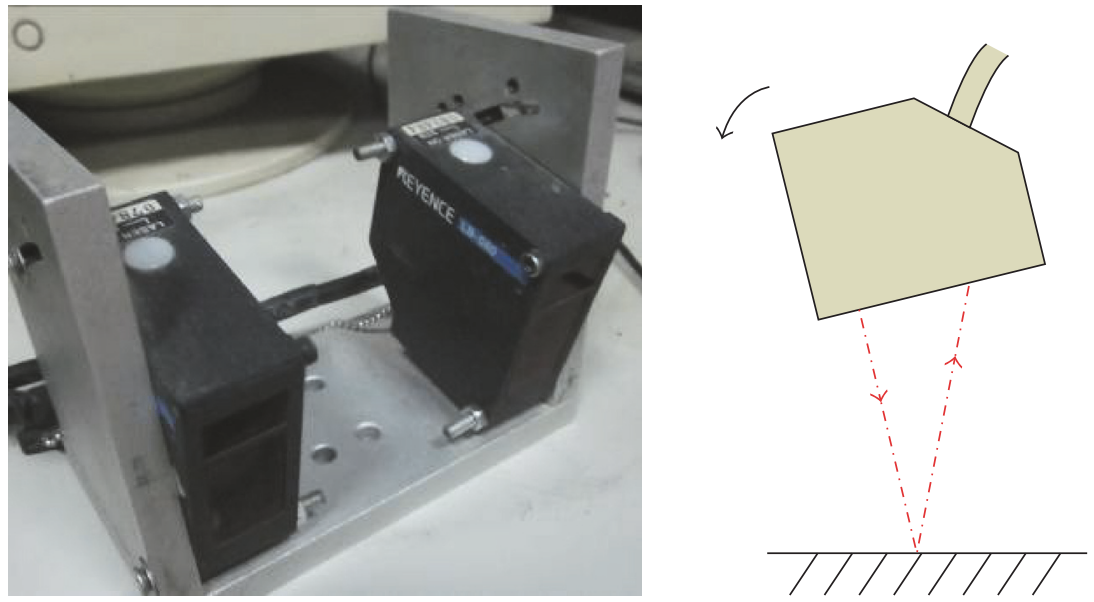

FIgURE 2: KEYENCE laser displacement sensors.
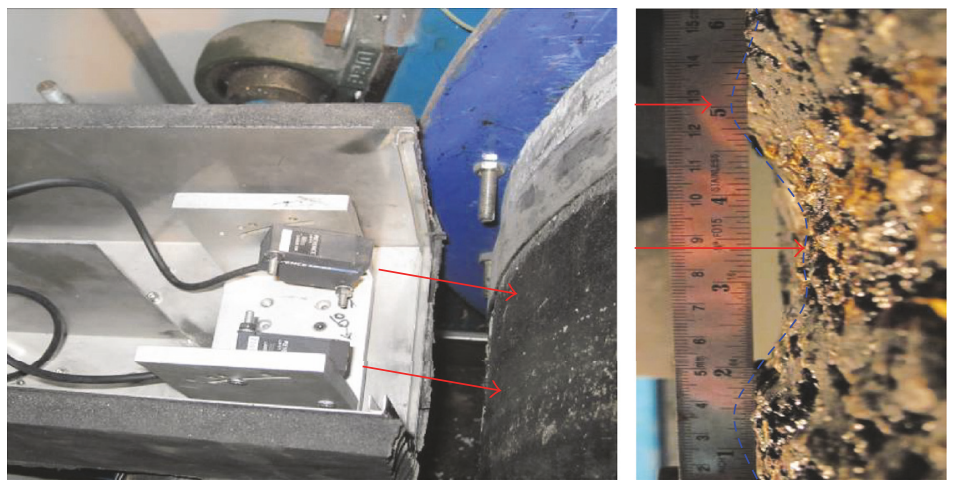

FIGURE 3: Setup of laser displacement sensors. The red arrows refer to the position where laser light is pointing at.

$60^{\circ} \mathrm{C}$ was selected as temperature [5]. We noticed that the specimens heat preservation time could not be below 5.5 hours.

The DWPA uses a curved mold and curved specimens (as shown in Figure 4). The outside diameter of each specimen is $1000 \mathrm{~mm}$ and inside diameter is $900 \mathrm{~mm}$. The inner arc length is $306 \mathrm{~mm}$ and the width is $300 \mathrm{~mm}$. The specimen is compressed with an improved flat head roller (as shown in Figure 5). The rolling repetitions are 70 times. Usually, the thickness of the specimen is $50 \mathrm{~mm}$; however, for special requirements, it can be increased to $65 \mathrm{~mm}$.

\section{Test Design}

In this study, we performed rutting with APA, Chinese standard rutting test, and also the new rutting tester at the same time. Based on a comparison of different equipment, we validated both accuracy and reliability of the new rutting measurement system. Three types of asphalt were used such as 70\# pavement asphalt, SBS modified asphalt, and high modified asphalt (Table 1). Necessary tests were performed such as asphalt penetration, asphalt softening point, and ductility. The mixture proportion was determined via Marshall
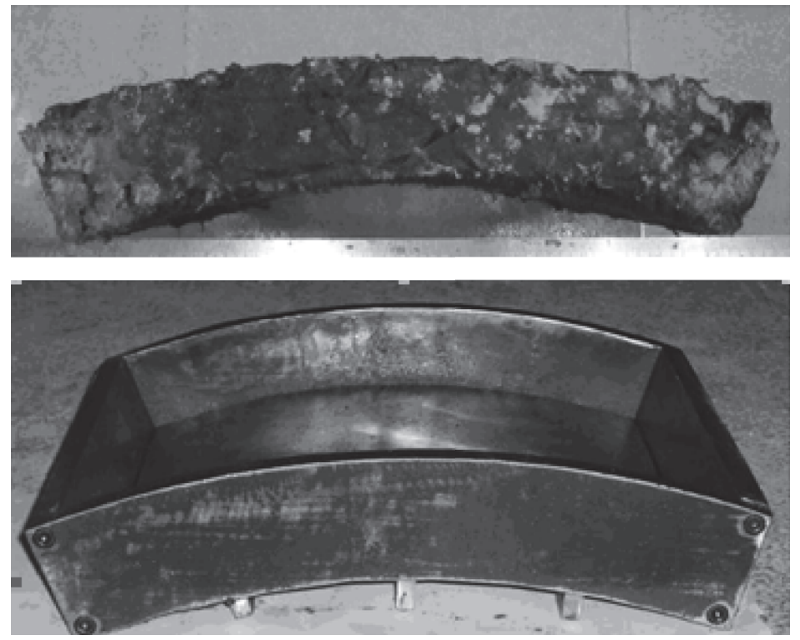

FIGURE 4: Curved specimen and its mold.

Test. In total, six different asphalt mixtures, including three representative gradations, were used (as shown in Table 2): dense granular compositions asphalt concrete $\mathrm{AC}-13 \mathrm{C}$ and 

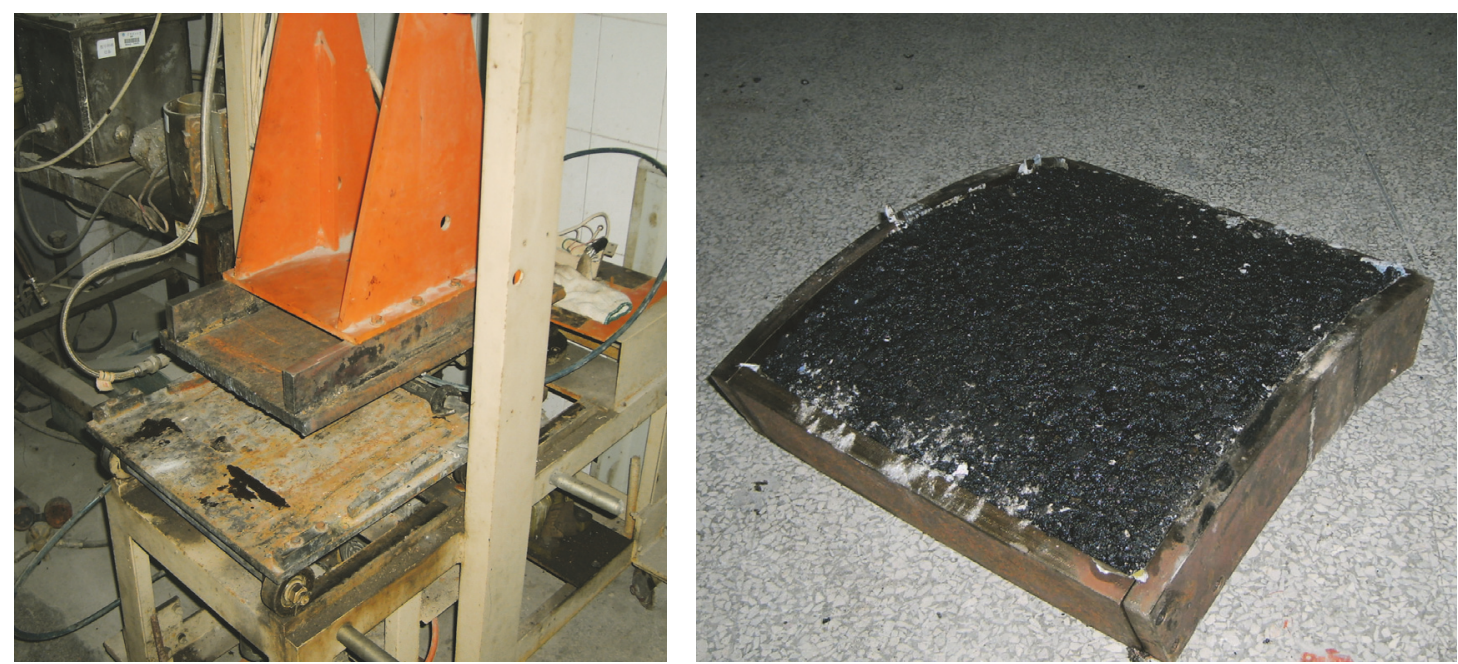

FIGURE 5: Flat head roller and compacted specimen.

TABLE 1: Technical parameters of asphalt.

\begin{tabular}{lccc}
\hline Asphalt & $T_{\mathrm{P}}(0.1 \mathrm{~mm})$ & $T_{\mathrm{SP}}\left({ }^{\circ} \mathrm{C}\right)$ & $D(\mathrm{~cm})$ \\
\hline 70\# paving grade asphalt & 67 & 49.8 & 14 \\
SBS modified asphalt & 58.5 & 71.4 & 34.2 \\
High modified asphalt & 36.5 & 79.5 & 22.5 \\
\hline
\end{tabular}

AC-13F, skeleton dense asphalt mixture SMA-13, and MLB13. Among these, the MLB-13 mixture was designed via the multilevel mixing method [21-23].

\section{Test Results and Data Analysis}

4.1. Rutting Test Result. Figure 3 shows the results for the DWPA rutting test. Figure 6 shows the DWPA loading system for the average of different materials, determining the rutting depth after the test. The test data shows that, after 8000 repetitions, the $\mathrm{AC}-13 \mathrm{C}$ mixture with the $70 \#$ paving grade asphalt had the deepest rut, while the MLB-13 mixture with the SBS modified asphalt had the smallest rut.

Furthermore, the DWPA rutting test significantly distinguished the influence of asphalt type on the rutting performance of mixture. For the same gradation (AC-13C), the rut depth was reduced with a simultaneous reduction of the asphalt penetration, which agreed with existing research and engineering practice. DWPA could also identify the influence of the gradation. For mixtures with the same SBS modified asphalt, the rut depths of MLB-13 and SMA-13 mixtures were small, while the rut depth of the AC-13F mixture was relatively deep. Therefore, the DWPA rutting measurement system is stable and fully achieves the design specification requirements. Secondly, the DWPA rutting test can be used for a rutting performance evaluation of the asphalt mixture.

Figure 7 and Table 3 show the results of APA rutting test and Chinese standard rutting test, respectively. Figure 7

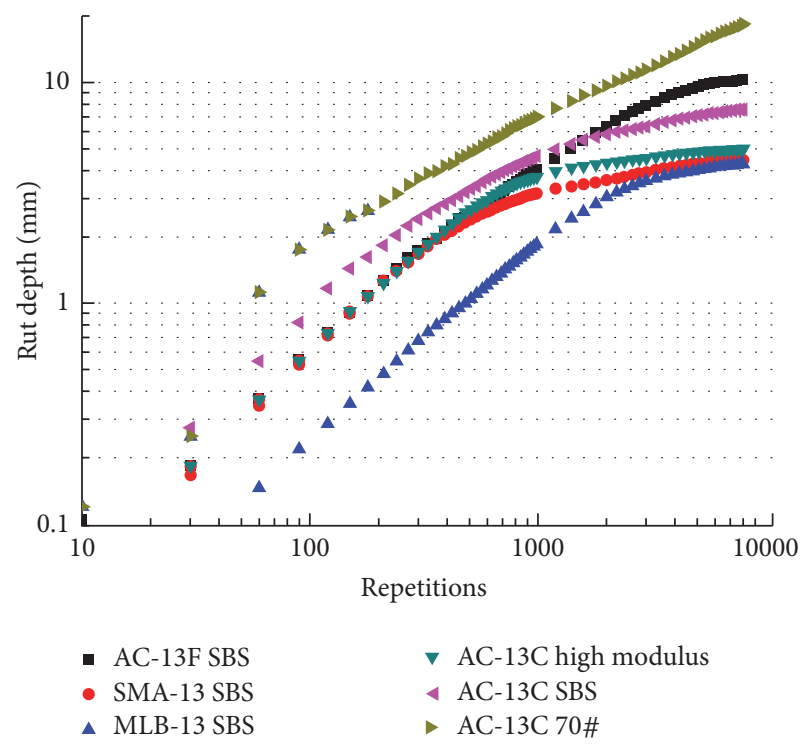

FIGURE 6: Average cumulative DWPA rutting.

shows that the APA test results and the DWPA test results were identical: the AC-13C mixture with 70\# asphalt showed the worst rutting performance, while the AC-13F mixture with SBS modified asphalt achieved second place. This was because the former used 70\# paving grade asphalt, which was not as good as the polymer modified bitumen and the latter used weaker gradation. The rutting performance of the MLB-13 mixture was the best. From these results, we noticed that both DWPA test and APA test were able to distinguish different rutting performances of asphalt mixtures; however, due to the different characteristics of the test equipment, final rut depths were different. Under the same load repetitions (the APA test defined the load wheel back and forth reciprocating movement for a loading cycle, and one loading cycle meant two repetitions. The DWPA test 
TABLE 2: Mix design information of asphalt mixtures.

\begin{tabular}{|c|c|c|c|c|c|c|}
\hline Granular composition & AC-13F & AC-13C & AC-13C & AC-13C & SMA-13 & MLB-13 \\
\hline Asphalt & $\begin{array}{l}\text { SBS modified } \\
\text { asphalt }\end{array}$ & $\begin{array}{l}\text { SBS modified } \\
\text { asphalt }\end{array}$ & $\begin{array}{l}\text { 70\# paving } \\
\text { grade asphalt }\end{array}$ & $\begin{array}{l}\text { High modified } \\
\text { asphalt }\end{array}$ & $\begin{array}{l}\text { SBS modified } \\
\text { asphalt }\end{array}$ & $\begin{array}{l}\text { SBS modified } \\
\text { asphalt }\end{array}$ \\
\hline Asphalt aggregate ratio (\%) & 4.9 & 4.3 & 4.4 & 4.3 & 5.9 & 4.8 \\
\hline 16 & 100 & 100 & 100 & 100 & 100 & 100 \\
\hline 13.2 & 100 & 90 & 90 & 90 & 89 & 81 \\
\hline 9.5 & 85 & 68 & 68 & 68 & 63 & 69 \\
\hline 4.75 & 68 & 38 & 38 & 38 & 25 & 49 \\
\hline 2.36 & 50 & 24 & 24 & 24 & 19 & 31 \\
\hline 1.18 & 38 & 15 & 15 & 15 & 15 & 21 \\
\hline 0.6 & 28 & 10 & 10 & 10 & 14 & 15 \\
\hline 0.3 & 20 & 7 & 7 & 7 & 13 & 12 \\
\hline 0.15 & 15 & 5 & 5 & 5 & 12 & 10 \\
\hline 0.075 & 8 & 4 & 4 & 4 & 10 & 6 \\
\hline
\end{tabular}

TABLE 3: Results of the Chinese standard rutting test.

\begin{tabular}{lccc}
\hline Granular composition & Asphalt & Rut depth $(\mathrm{mm})$ & Dynamic stability (time/mm) \\
\hline AC-13F & SBS modified asphalt & 3.824 & 2543.3 \\
MLB-13 & SBS modified asphalt & 1.925 & 7076.4 \\
SMA-13 & SBS modified asphalt & 2.019 & 7254.8 \\
AC-13C & High modified asphalt & 1.720 & 6289.2 \\
AC-13C & SBS modified asphalt & 2.507 & 3753.6 \\
AC-13C & 70\# paving grade asphalt & 5.393 & 1695.7 \\
\hline
\end{tabular}

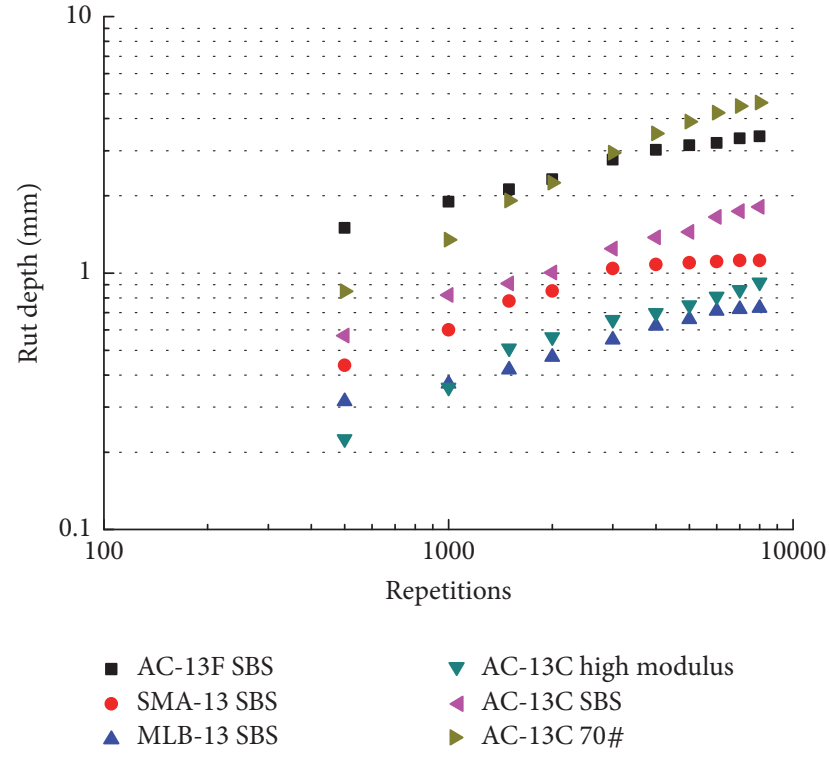

Figure 7: Average cumulative APA rutting.

defined one rotation of the specimen wheel for a loading cycle, meaning one repetition), the rut depths of the mixture under the DWPA test were higher compared to the APA test. Thus, it can be concluded that the DWPA rutting test allows for more rigorous test conditions, thus simulating real traffic conditions of the environment and load characteristics.

Table 3 shows that the orders of rutting performance of mixtures for both the Chinese rutting test and the DWPA test were basically identical. According to the rut depths for both tests, the main difference was the performance of the MLB-13 mixture and the AC-13C mixture with high modified asphalt. The rut depth of the AC-13C mixture with the high modified asphalt mixture was smaller than for the MLB-13 mixture, which is in contrast to the DWPA test. In fact, in China we actually used dynamic stability index to reflect the rutting performance of asphalt mixture during the high temperature season, expressed as the repetition of the passes of the wheel to generate a deformation of $1 \mathrm{~mm}$. Using the dynamic stability for evaluation standard, the SMA-13 mixture showed the best antirutting ability, followed by the MLB-13 mixture with the same SBS asphalt. Furthermore, the AC-13C mixture with 70\# pavement petroleum asphalt mixture showed the worst antirutting ability. In summary, using the Chinese rutting test results as benchmark, the rut depth index under DWPA test was consistent with the Chinese rutting test results. When using the dynamic stability evaluation index, the DWPA test was generally able to reflect the rutting performance of different materials.

4.2. Evaluation Index and Choice of Evaluation Standard. The European Union standards for rutting tests mainly utilize 
TABLE 4: Results of $C_{\text {DWPA }}$.

\begin{tabular}{lccc}
\hline Granular composition & Asphalt & $C_{\text {DWPA }} /($ time $/ \mathrm{mm})$ & Remark \\
\hline AC-13F & SBS modified asphalt & 850.3 & 2426.5 \\
MLB-13 & SBS modified asphalt & 2359.3 & $C_{\text {DWPA }}=6000 /\left(d_{2}-d_{1}\right)$ \\
SMA-13 & SBS modified asphalt & 1843.5 & \\
AC-13C & High modified asphalt & 1213.0 & 486.6 \\
AC-13C & SBS modified asphalt & \\
AC-13C & 70\# paving grade asphalt & \\
\hline
\end{tabular}

three indexes: deformation slope WTS ( $\mathrm{mm} / 10^{3}$ times), total deformation (usually indicating the rut depth after 10000 cycles), and the percentage of rut depth (PRD). The evaluation index in different countries depends on the prevalent conditions and situations in each country; a good example is France, which frequently uses total deformation. In the UK, the deformation slope and the total deformation are used as key indicators. Dynamic stability applies for China, Germany, and Japan. However, although the Chinese standards and the Hamburg rutting test use the same deformation slope index, the selected time points are different during the calculation.

In this study, three rutting devices were used to perform the rutting test. Even though each has its own characteristic, all were able to distinguish between the worst antirutting performance (AC-13C mixture with 70\# asphalt) and best good antirutting performance (MLB-13 mixture) mixtures; however, there is still variation in the performance of the mixture. Furthermore, we cannot ignore different factors that influence the rutting performance. It can be noticed that the APA test uses the total rut depth as the evaluation index (AASHTO TP 63-07 provides the maximum deformation measured after 8000 cycles [23-25]), while the Chinese standard rutting test uses dynamic stability. With regard to the DWPA test, the appropriate evaluation index still requires further discussion.

4.2.1. Deformation Slope Index. The asphalt mixture rutting test curve generally includes three stages: the supplementary compaction stage, the shear deformation stage, and the shear failure stage. Chinese's dynamic stability indexes are calculated at $45 \mathrm{~min}$ and $60 \mathrm{~min}$ according to the displacements, essentially reflecting the creep properties of the mixture during the shear deformation stage. Related research indicated that it usually took $120 \mathrm{~s}$ for the mixture to end the supplementary compaction stage, which meant adopting between $45 \mathrm{~min}$ and $60 \mathrm{~min}$ as the calculation time to guarantee that the amount of deformation was in the shear deformation stage. However, the DWPA test provides more severe test conditions, which means that direct application to the calculation method in Chinese standard may cause error.

If flow deformation happened during the shear deformation stage, the belt of the wheel track would be concave and the edge of the wheel track convex. Therefore, we can trace the change of the height at the edge of the wheel track. As a result, we can identify whether the mixture entered the shear deformation stage.

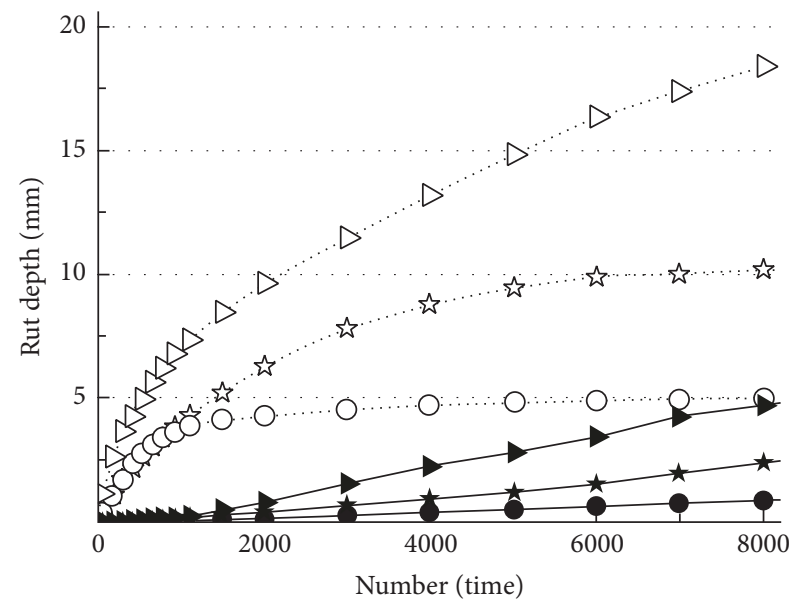

AC AC-13F total deformation $\rightarrow$ AC-13F convex amount
O. MLB-13 total deformation
D. AC-13 total deformation $\rightarrow$ MLB-13 convex amount

Figure 8: Decomposition of DWPA rutting depth.

Figure 8 shows that the deformation times were different between mixtures during the shear deformation phase. The AC-13 mixture with 70\# asphalt was the first to show signs of shear deformation (after about 300 repetitions), while the MLB-13 mixture, approximately after 900 repetitions. Within the creep stability period, the deformations were more accurate; therefore, for the first calculation point $\left(d_{1}\right)$ we chose 2000 repetitions for the total deformation as the creep slope, as during the test performance shear failure did not occur in the materials. We chose 8000 repetitions for the total deformation for the second calculation point $\left(d_{2}\right)$. In this study, the representation of the deformation slope is (time $/ \mathrm{mm}$ ). Table 4 presents the results from the calculation.

According to the calculation results shown in Table 4, we found $C_{\text {DWPA }}$ to be smaller than the dynamic stability of the Chinese standard rutting test, as the weight of the test wheels $(0.78 \mathrm{kN}$ for the Chinese standard rutting test total axle load) was smaller than that of the DWPA test. We realized that when we used the $C_{\mathrm{DWPA}}$ index as the evaluation standard, we can also receive similar results: rutting performance of $\mathrm{AC}$ 13C mixture with 70\# asphalt was the worst, and MLB-13 and SMA-13 mixture with SBS asphalt was the best. This analysis revealed that the use of the $C_{\mathrm{DWPA}}$ index as evaluation standard was feasible. 
After referring to the Chinese specification [5], we preliminary determined the rutting performance evaluation standard for the DWPA test: $60^{\circ} \mathrm{C}$ for the test temperature, $2.5 \mathrm{kN}$ for the axle load, and $0.7 \mathrm{MPa}$ for the tire pressure. The deformation slope $C_{\mathrm{DWPA}}$ should not be below 300 times $/ \mathrm{mm}$ for the ordinary asphalt mixture (70\#); not below 900 times $/ \mathrm{mm}$ for the modified asphalt mixture and also not below 1000 times $/ \mathrm{mm}$ for the stone mastic asphalt (SMA) mixture. The important factor to take into consideration is that the index still requires field-measured data for calibration. Our target is to conduct a follow-up research study focusing on this.

4.2.2. Total Deformation Index. The total rutting deformation slope is intuitive; however, the indexes are easily influenced by the initial degree of compaction of the specimen. Lower initial degrees of compaction of the specimen will result in a larger total amount of deformation. As shown in Figure 8, we noticed that, after 2000 repetitions, the rutting depth of different materials stabilized. At that moment, the total deformation was sufficient to characterize the performance of the antirutting mixture. With reference to the APA test, the total deformation for the evaluation standard of the DWPA criteria we chose was as follows: after 2000 repetitions, the rut depth did not exceed $10 \mathrm{~mm}$, or after 8000 repetitions, the rut depth did not exceed $15 \mathrm{~mm}$. However, this criterion still requires actual engineering (on-field) correction.

\section{Rutting Index Correlation Analysis}

The previous analysis revealed that deformation slope and total deformation indexes could be used as evaluation index of DWPA rutting test. Among them, the dynamic deformation slope reflects the rutting stability growth process, an index that represents the rutting growth speed, but cannot confirm the position of rutting curve. Comprehensively considering the total deformation of the mixture, it represents the supplemental compaction and shear deformation, which can intuitively evaluate the rutting resistance performance of the material. However, we still need one single index for the DWPA test to appropriately describe the rutting performance and to guide the material design for the DWPA test. Therefore, it is necessary to analyze the results of the rutting test with grey relational analysis technology [26].

5.1. Grey Relational Analysis Technology. The theory of a grey system was proposed and developed in 1980 by Professor Deng Zulong, a famous scholar in China. Its main contents include a theoretical system based on the "grey hazy set"; this analytic system is based on the Obscure Correlation Space and the Obscure Sequence Generation Method System and uses the grey model (G, M) as core model system [27, 28]. Its application areas include grey correlation analysis, grey prediction, grey decision, and grey predictive control.

Among these, grey association refers to the indeterminate association between things. The grey relational analysis is a method for analyzing the degree of correlation for each factor in the system or a method of quantitative analysis of the development trend of the dynamic process of the system.
It is based on the geometric relationship of the series or the degree of similarity of the curve that determines the degree of correlation between all factors. If the shape of the curves is similar, the degree of correlation is closer to one (1); otherwise, the correlation will be closer to zero (0). The grey relational analysis method has no special requirements regarding the sample size. The analysis does not have to obey the typical distribution rule, and the factors are unified into the system for comparison and analysis; therefore, it is suitable for the analysis of the rutting test results via different test methods. The calculation steps are as follows.

Firstly, the evaluation index system is determined according to the analysis target. Then, the reference data column and the comparison data column are determined. The reference data column should be an ideal comparison standard, while the reference data column can be constructed with the optimal value (or the worst value) of each index:

$$
X_{0}^{\prime}=\left\{x_{0}^{\prime}(1), x_{0}^{\prime}(2), x_{0}^{\prime}(3), \ldots, x_{0}^{\prime}(m)\right\} .
$$

In the second step, the dimension of the indicator data is turned to be dimensionless and can be written in the formation of the following matrix:

$$
\begin{aligned}
\left(X_{0}, X_{1}, X_{2}, \ldots, X_{n}\right) & \\
& =\left(\begin{array}{cccc}
x_{0}(1) & x_{1}(1) & \cdots & x_{n}(1) \\
x_{0}(2) & x_{1}(2) & \cdots & x_{n}(2) \\
\vdots & \vdots & \ddots & \vdots \\
x_{0}(m) & x_{1}(m) & \cdots & x_{n}(m)
\end{array}\right) .
\end{aligned}
$$

The dimensionless methods commonly used are averaged method and initialized method, respectively:

$$
\begin{aligned}
& x_{i}(k)=\frac{x_{i}^{\prime}(k)}{(1 / m) \sum_{k=1}^{m} x_{i}^{\prime}(k)}, \\
& x_{i}(k)=\frac{x_{i}^{\prime}(k)}{x_{i}^{\prime}(1)},
\end{aligned}
$$

where $i=0,1,2, \ldots, n ; k=1,2,3, \ldots, m$.

The third step is to calculate the absolute difference between each comparison sequence and the reference sequence $\left|x_{0}(k)-x_{i}(k)\right|$ and to determine the $\min _{i=1}^{n} \min _{k=1}^{m}\left|x_{0}(k)-x_{i}(k)\right|$ and $\max _{i=1}^{n} \max _{k=1}^{m}\left|x_{0}(k)-x_{i}(k)\right|$.

The last step is to calculate the grey correlation coefficient:

$$
\begin{aligned}
& \zeta_{i}(k) \\
& =\frac{\min _{i} \min _{k}\left|x_{0}(k)-x_{i}(k)\right|+\rho \cdot \max _{i} \max _{k}\left|x_{0}(k)-x_{i}(k)\right|}{\left|x_{0}(k)-x_{i}(k)\right|+\rho \cdot \max _{i} \max _{k}\left|x_{0}(k)-x_{i}(k)\right|},
\end{aligned}
$$

where $\rho$ is the resolution factor (from 0 to 1 ). The smaller the resolution factor is, the greater the difference between factors will be. In general, $\rho$ equals 0.5 .

5.2. Grey Relational Analysis of Rutting Test Results. Five rutting indexes were used for the grey relational analysis in 
TABLE 5: Series of grey relational analysis.

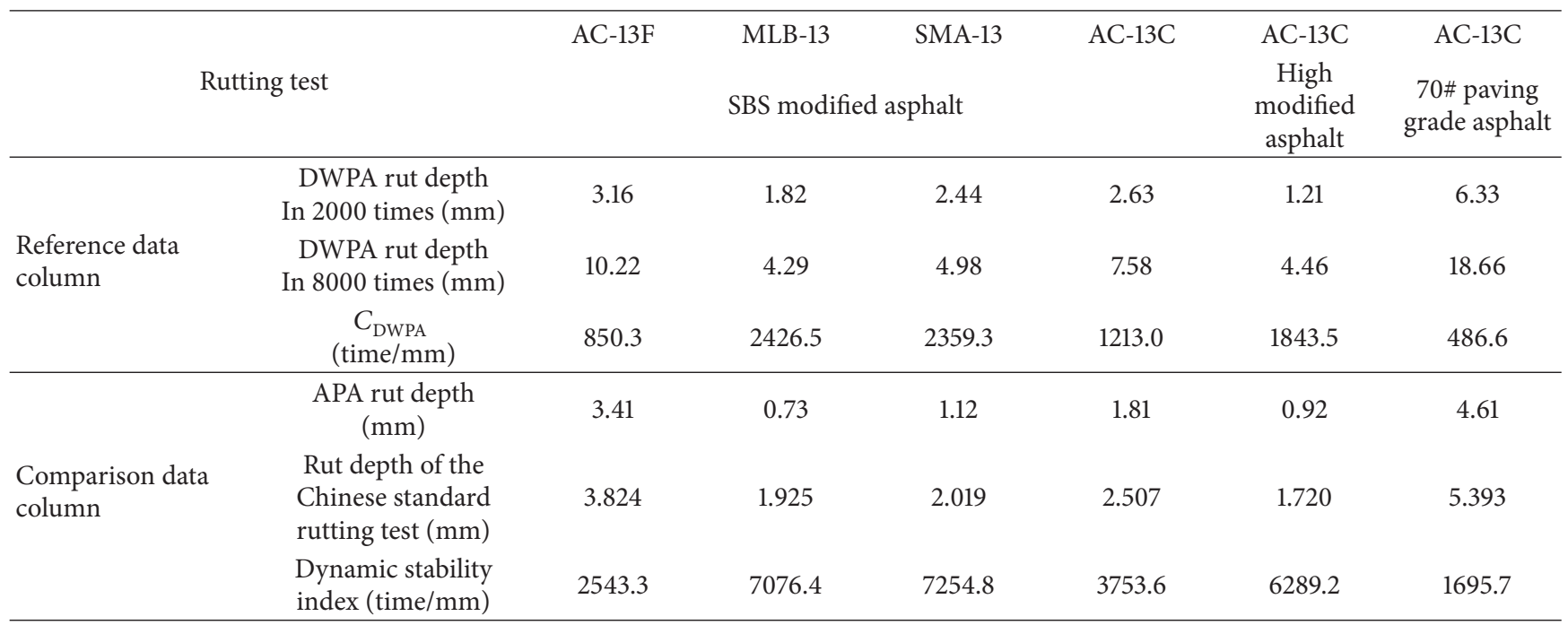

TABLE 6: Results of grey relational analysis.

\begin{tabular}{lccc}
\hline Index & APA rut depth & Rut depth of the Chinese standard rutting test & Dynamic stability index \\
\hline DWPA rut depth in 2000 times & 0.9985 & 0.9858 & 0.3365 \\
DWPA rut depth in 8000 times & 0.9990 & 0.9868 & 0.3365 \\
$C_{\text {DWPA }}$ & 0.7513 & 0.7523 & 0.9450 \\
\hline
\end{tabular}

this research, namely, the rut depth index of the APA test, the depth index of the Chinese standard rutting test, the dynamic stability index, the depth index of the DWPA test, and the dynamic stability index $C_{\text {DWPA }}$. Therefore, the depth of the DWPA rutting test (2000 and 8000 repetitions) and the dynamic stability index $C_{\mathrm{DWPA}}$ were used as reference data columns, with the remainder of the indicators as the comparison data column. Data for analysis are shown in Table 5.

The correlation between the reference series and the comparison sequence was calculated vie the grey relational analysis method. The calculation process was simplified with MATLAB. The results are shown in Table 6.

According to Table 6, we found good correlation degree among DWPA rut depth index, APA rut depth, and rut depth of the Chinese standard rutting test. However, a poor correlation degree was found with the other two indicators. To further analyze the comprehensive correlation degree between indexes of each rut test, the correlation order of the index series was calculated to reflect the correlation between reference series and comparison sequence. The calculation method is as follows:

$$
r_{0 i}=\frac{1}{m} \sum_{k=1}^{m} \zeta_{i}(k) .
$$

From Formula (5), the correlation orders of DWPA rutting depth index with the other three indicators were 0.7736 (2000 repetitions) and 0.7741 (8000 repetitions) and the correlation orders of $C_{\mathrm{DWPA}}$ with the other three indicators were 0.8162 . This result indicated that the $C_{\mathrm{DWPA}}$ index was more suited to reflect the rutting resistance of the material, which highly correlated with the APA rutting index and the rutting test index in China. Furthermore, this result showed that repetitions of 2000 and 8000 were appropriate to calculate the $C_{\text {DWPA }}$ index and it was also reasonable to assume that it was better to characterize the rutting resistance of the material via the deformation slope of the creep deformation stage, which was consistent with specifications.

Therefore, the criteria for DWPA rutting test are as follows: the $C_{\text {DWPA }}$ index of the material is calculated from the rut depth of 2000 and 8000 repetitions at a test temperature of $60^{\circ} \mathrm{C}$, the axle load is $2.5 \mathrm{kN}$, and the tire pressure is $0.7 \mathrm{MPa}$. According to the technical requirements in the existing specification, and with reference to the test results of each material, the technical requirements of the $C_{\mathrm{DWPA}}$ index could be determined: for a plain asphalt mixture, it is not below 300 times $/ \mathrm{mm}$, for the dense gradation with modified asphalt mixture, it is not below 900 times $/ \mathrm{mm}$, and for SMA mixture, it is not below 1000 times $/ \mathrm{mm}$.

\section{Conclusion}

This study aimed to establish the evaluation index of the Driving Wheel Pavement Analyzer via comparative examination between the APA test and the Chinese standard rutting test 
and to validate its feasibility, reliability, and accuracy. We preliminary established a corresponding rutting performance evaluation standard for DWPA test. Based on the analysis of the test results, we noticed that the total deformation index from three types of rutting methods basically yield the same results; furthermore, with regard to the deformation slope index, subtle differences were found between the DWPA test results and the Chinese standard rutting test results. Furthermore, the $C_{\mathrm{DWPA}}$ index was better to reflect the rutting resistance of the material for DWPA test, which highly correlated with the APA rut depth and the rutting test index in China according to the grey relational analysis results.

Compared to other rutting test methods, the DWPA test provides more rutting information. One of the directions for future research is to deeply analyze these data and to explore the mechanism of the material creep process. Secondly, the DWPA test had better applicability and can be used for materials in some special sections such as long slopes, steep slopes, and high temperature environments. Finally, indoor tests (laboratory) and actual pavement rutting depths were inevitably different; therefore, future research will focus on fitting the actual rutting performance and its prediction. For this, references can be made to the South Africa mobile load simulator (MMLS3) test evaluation method [18], combined with asphalt pavement reverse design techniques to reshape the actual pavement structure via indoor tests and onfield long-term observations, thus establishing a relationship between indoor and outdoor rutting depth.

\section{Conflicts of Interest}

The authors declare that there are no conflicts of interest regarding the publication of this paper.

\section{Acknowledgments}

The authors would like to thank the National Natural Science Foundation of China (nos. 51568007, 51378224, and 51208212), Natural Science Foundation of Guangdong Province (no. 2014A030310272), and Systematic Project of Guangxi Key Laboratory of Disaster Prevention and Structural Safety (no. 2016ZDX007) for funding this research.

\section{References}

[1] J. Ahmad, M. Y. Abdul Rahman, and M. R. Hainin, Rutting Evaluation of Dense Graded Hot Mix Asphalt Mixture, Institute of Infrastructure Engineering and Sustainable Management (IIESM), Faculty of Civil Engineering, University Teknologi MARA, 40450, Shah Alam, Malaysia.

[2] O. Sirin, H.-J. Kim, M. Tia, and B. Choubane, "Comparison of rutting resistance of unmodified and SBS-modified Superpave mixtures by accelerated pavement testing," Construction and Building Materials, vol. 22, no. 3, pp. 286-294, 2008.

[3] Y. H. Huang, Pavement Analysis and Design, Pearson Education Inc., Cranbury, NJ, USA, 2004.

[4] National Cooperative Highway Research Program (NCHRP), Guide for mechanistic-empirical design of new and rehabilitated pavement structures, Transportation Research Board, Washington, DC, USA, 2004.

[5] JTG F40-2004, “Technical Specifications for Construction of Highway Asphalt Pavement," Tech. Rep.

[6] B. Javilla, L. Mo, F. Hao, B. Shu, and S. Wu, "Multi-stress loading effect on rutting performance of asphalt mixtures based on wheel tracking testing," Construction and Building Materials, vol. 148, pp. 1-9, 2017.

[7] P. Chaturabong and H. U. Bahia, "Mechanisms of asphalt mixture rutting in the dry Hamburg Wheel Tracking test and the potential to be alternative test in measuring rutting resistance," Construction and Building Materials, vol. 146, pp. 175-182, 2017.

[8] J. Zhang, L. F. Walubita, A. N. M. Faruk, P. Karki, and G. S. Simate, "Use of the MSCR test to characterize the asphalt binder properties relative to HMA rutting performance - a laboratory study," Construction and Building Materials, vol. 94, Article 6791, pp. 218-227, 2015.

[9] V. Gladkikh, E. Korolev, V. Smirnov, and I. Sukhachev, "Modeling the Rutting Kinetics of the Sulfur-extended Asphalt," in Proceedings of the 15th International Scientific Conference 'Underground Urbanisation as a Prerequisite for Sustainable Development', ACUUS 2016, pp. 1417-1423, September 2016.

[10] F. Xiao, D. A. Herndon, S. Amirkhanian, and L. He, "Aggregate gradations on moisture and rutting resistances of open graded friction course mixtures," Construction and Building Materials, vol. 85, pp. 127-135, 2015.

[11] S. Khan, M. Nagabhushana, D. Tiwari, and P. Jain, "Comparison of Uni and Bi-directional Load Induced Rutting in Flexible Pavement with Accelerated Pavement Testing Facility (APTF)," Transportation Research Procedia, vol. 17, pp. 521-528, 2016.

[12] L. F. Walubita, A. N. M. Faruk, J. Zhang, X. Hu, and S. I. Lee, "The Hamburg rutting test-effects of HMA sample sitting time and test temperature variation," Construction and Building Materials, vol. 108, pp. 22-28, 2016.

[13] H. Özen, "Rutting evaluation of hydrated lime and SBS modified asphalt mixtures for laboratory and field compacted samples," Construction and Building Materials, vol. 25, no. 2, pp. 756-765, 2011.

[14] T. Aschenbrener, "Comparison of results obtained from the French rutting tester with pavements of known field performance," Colorado Department of Transportation, Report no: CDOT-DTD-R-92-11, October 1992.

[15] C. Pan, T. D. White, and T. R. West, Effect of fine aggregate angularity on asphalt mixture performance, Purdue University, West Lafayette, USA, 1999.

[16] J. Stiady, A. Hand, and T. White, "Quantifying contributions of aggregate characteristics to HMA performance using PURWheel laboratory tracking device," in Proceedings of the Aggregate Contribution to Hot Mix Asphalt (HMA) Performance, pp. 1-15, December 2000.

[17] R. B. Mallick and J. A. Bergendahl, An Evaluation of Rutting and Shoving Potential of, and Chloride diffusion Through Hot Mix Asphalt (HMA) with Rosphalt, Worcester Polytechnic Institute: Civil and Environmental Engineering Department, 2004.

[18] A. Smit, F. de, F. Hugo, Y. Yeldirim et al., "A Discussion of MMLS3 Performance Testing of Laboratory Prepared HMA Slabs and Briquettes Compared with Hamburg and APA Wheel Tracking Tests," in CD-ROM Proceedings Second International APT Conference, Washington, DC, USA. 
[19] R. B. Powell, "Laboratory performance testing for the NCAT pavement test track," in Transportation Research Record 2003 002331, TRB, National Research Council, 2003.

[20] American Association of State Highway and Transportation Officials. (AASHTO) TP 63-07, "Determining rutting susceptibility of hot mix asphalt (HMA) using the asphalt pavement analyzer (APA)," in AASHTO Provincial Standards, Washington, DC, USA, 2007.

[21] S.-Y. Wang, F. Xiong, and T. Wei, "Summarization of technical development level of track measuring device," Technology of Highway and Transport, no. 3, pp. 32-35, 2007.

[22] Y.-M. Li, "Investigation on the wheel tracking test of bituminous mixture," China Journal of Highway and Transport, vol. 15, no. 3, pp. 56-60, 1992.

[23] A. L. Epps, T. Ahmed, D. C. Little, M. Y. Mikhail, and F. Hugo, "Performance assessment with the MMLS3 at WesTrack," in Proceedings of the Asphalt Paving Technology 2001, pp. 509-542, March 2001.

[24] T. F. Fwa, S. A. Tan, and L. Y. Zhu, "Rutting prediction of asphalt pavement layer using C-model," Journal of Transportation Engineering, vol. 130, no. 5, pp. 675-683, 2004.

[25] Y.-Z. Pang, D.-Y. Wang, and X.-N. Zhang, "Study on OpenGraded Mix Design," Journal of Highway and Transportation Research and Development, vol. 08, pp. 67-71, 2007.

[26] J.-L. Deng, Foundation of Grey Theory, Huazhong University of Science and Technology Press, 2002.

[27] B.-Z. Zhu, "Study and reviews on the essential methods of grey system," Systems Engineering-Theory \& Practice, vol. 4, pp. 5360, 1994.

[28] T. Fang, Image Processing Based Grey System Theory Mathematical Morphology, Jilin University, 2007. 

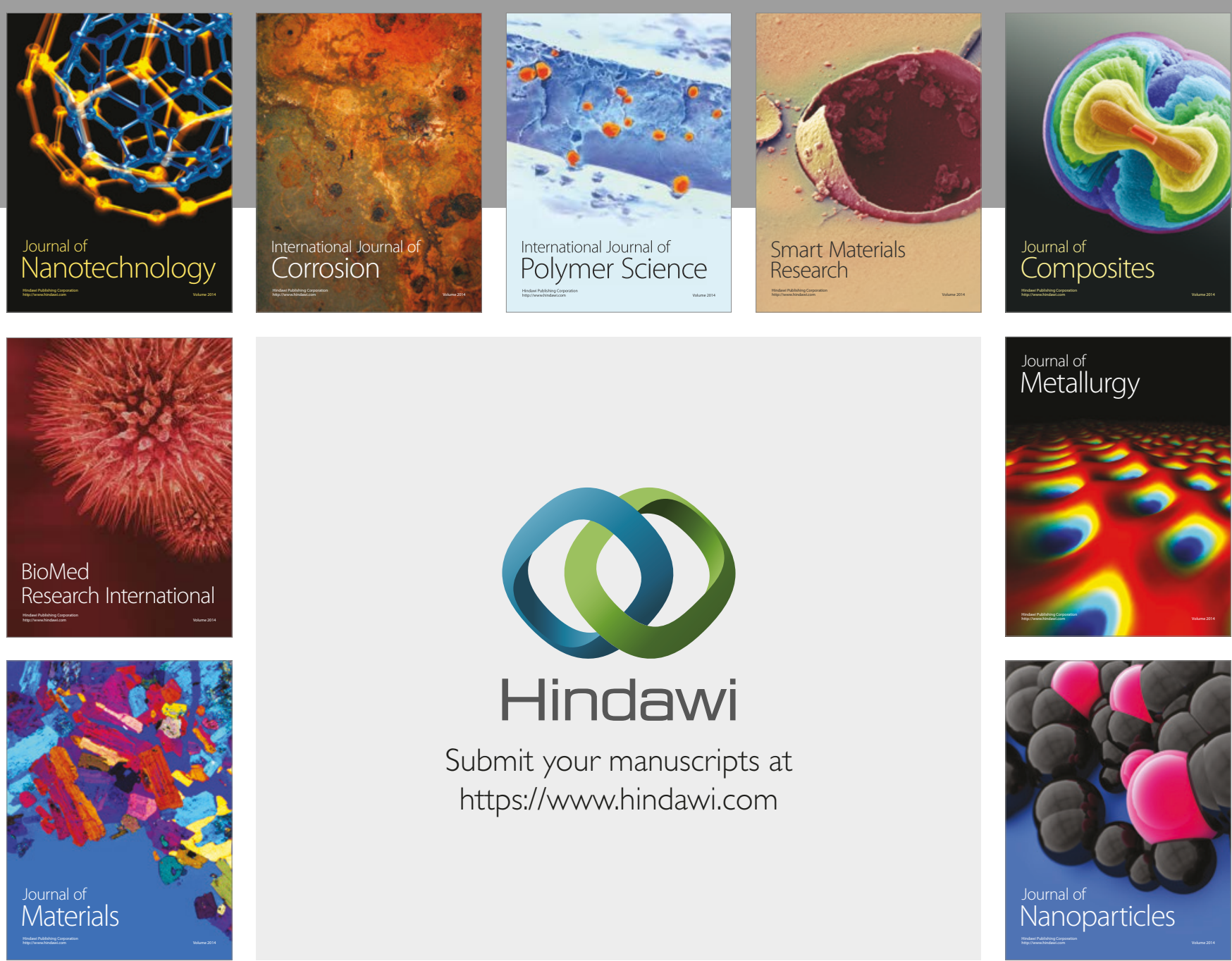

\section{Hindawi}

Submit your manuscripts at

https://www.hindawi.com
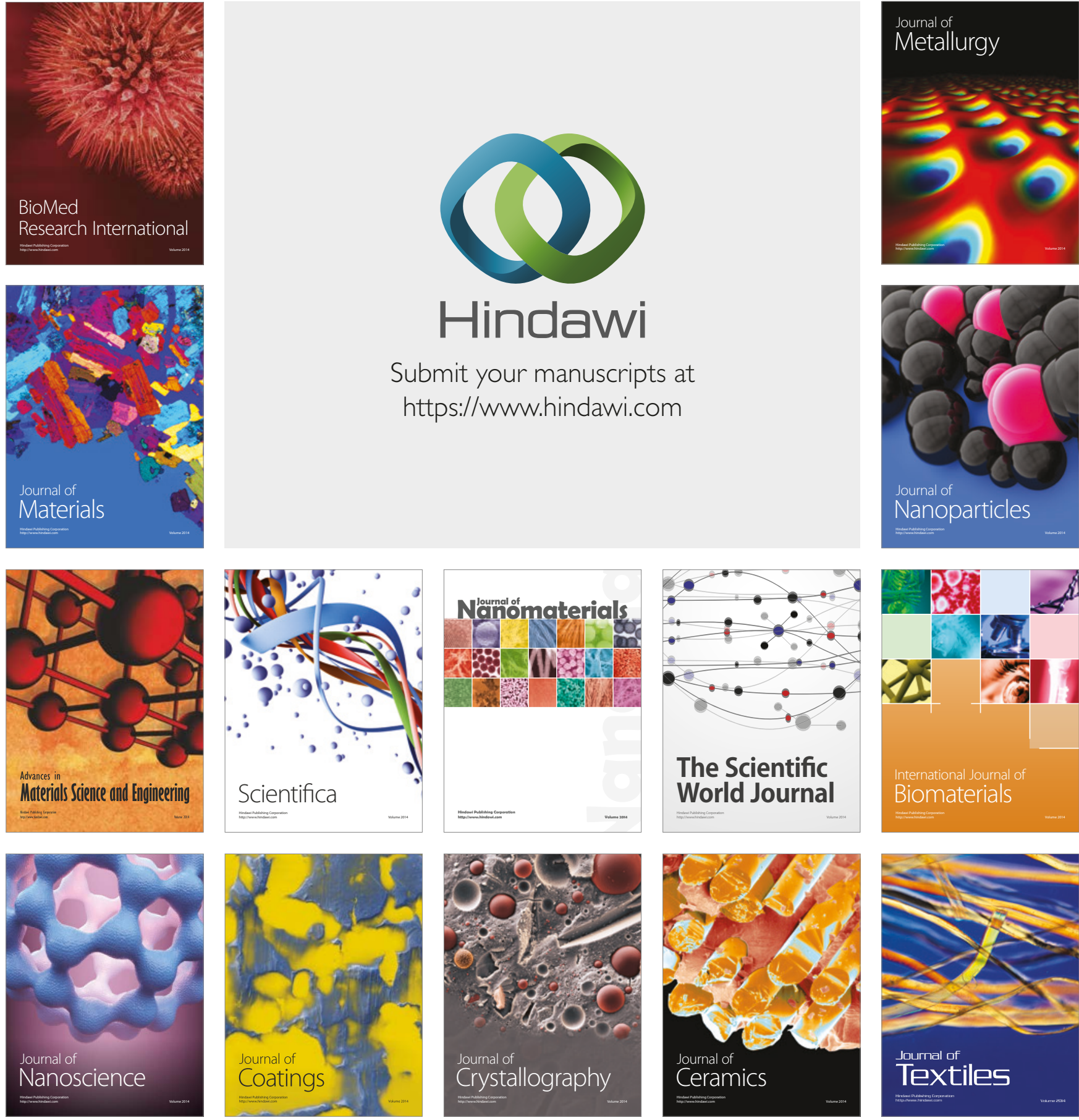

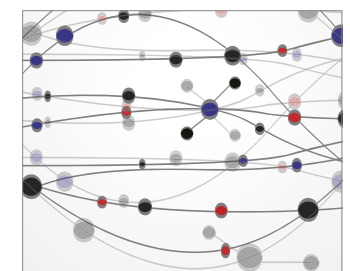

The Scientific World Journal
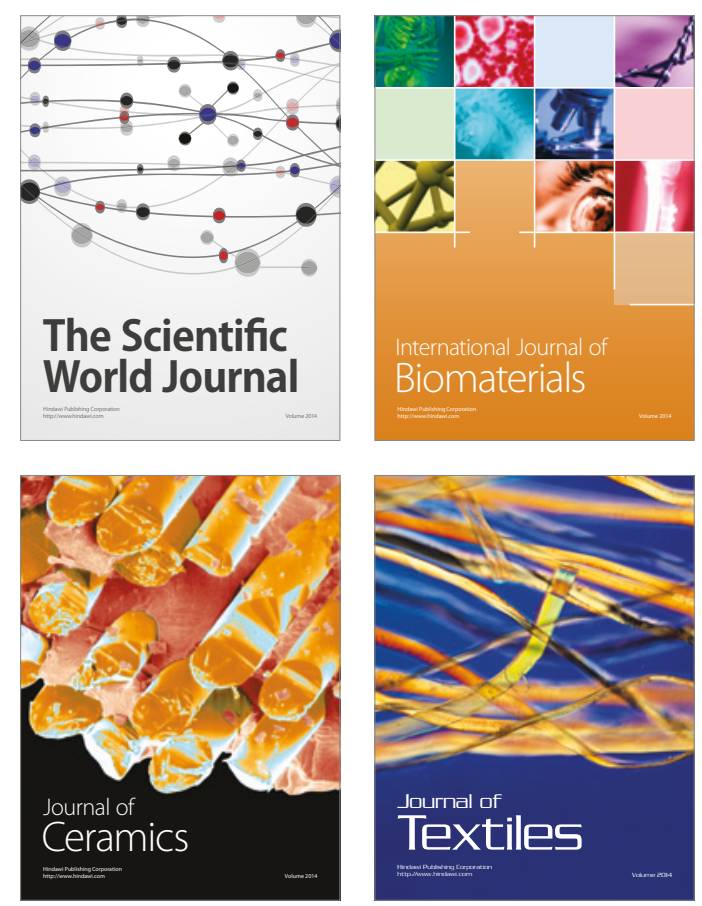